\title{
Effect of gamma-irradiation on the differential leukocyte count in fish Poecilia reticulata
}

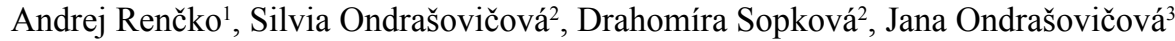 \\ ${ }^{1}$ University of Veterinary Medicine and Pharmacy, Department of Biology and Genetics, \\ Košice, Slovak Republic \\ ${ }^{2}$ University of Veterinary Medicine and Pharmacy, Department of Anatomy, Histology and Physiology, \\ Košice, Slovak Republic \\ ${ }^{3}$ Pavol Jozef Šafárik University, Faculty of Medicine, Department of Stomatology and Maxillofacial Surgery, \\ Košice, Slovak Republic \\ Received October 13, 2013 \\ Accepted July 23, 2014
}

\begin{abstract}
The study investigated the effect of a single gamma-irradiation with a ${ }^{60} \mathrm{Co}$ source at a dose of $20 \mathrm{~Gy}(1.05 \mathrm{~Gy} / \mathrm{min}$ ) on the guppy Poecilia reticulata (females, $\mathrm{n}=60$ ), which has not been determined before in this fish. We observed food intake, clinical symptoms, pathologicalanatomical and histological changes and differential leukocyte count in the irradiated guppies compared to the control ones. In the first days, timidity and lethargy were observed. The most prominent clinical symptoms observed were exophthalmia, emaciation and intravital haemorrhages. Livers of irradiated guppies were characterized by hepatic steatosis. Leukogram determinations were carried out on days 3, 7, 10, 15, and 20. Relative lymphopaenia was observed in irradiated fish and the mean relative monocyte count in irradiated guppies increased from 8.7 to 20.6 within 3 days. Other important values obtained from the leukogram included relative neutropaenia, eosinopaenia and basopaenia, observed on day 3 after irradiation.
\end{abstract}

Radiation, leukogram, guppy, clinical symptoms

Ionizing radiation is used in many fields of human activity. Beside the positive effects of radiation on live organisms, we are also aware of the negative effects that result in irradiation disease in mammals and birds when doses of radiation exceed certain levels (Beňová et al. 2007). Low doses can increase the risk of longer term effects, such as cancer.

Blood haematological indices are often used to assess the health status in fish. Our study focused on the effect of ionizing radiation at a dose of $20 \mathrm{~Gy}$ on the white blood cells for 20 days post-irradiation. Cells and tissues with high mitotic activity are most sensitive to radiation. Such tissues include blood and blood-forming organs (Lešník and Danko 2005). White blood cell count is an important indicator of the body's defence capabilities. Diagnosis and treatment of radiation sickness is difficult and long. One of the most important indicators of damage to the organism are the values of peripheral blood which change significantly shortly after irradiation with a low-dose (Waghmare et al. 2011). In addition to mutagenic and teratogenic effects, ionizing radiation also has genotoxic effects. However, not only gamma rays but X-rays at higher doses also cause chromosomal disorders, structural or numerical. Chromosomal aberrations in peripheral blood in metaphase in lymphocytes were observed at doses up to 6 Gy of X-rays (Chua et al. 2011). Bukhari et al. (2012) irradiated fish species Oreochromis mossambicus with ${ }^{60} \mathrm{Co}$ dose of $3 \mathrm{mGy}, 30 \mathrm{mGy}$, and $300 \mathrm{mGy}$ of gamma rays and observed significant changes in the structure of the liver, liver cell necrotisation, structural changes and vacuolisation of the liver cells. After irradiation of human peripheral blood, Vasumathy et al. (2012) observed 
apoptosis and significant reduction in the number of all types of leukocytes in relation to intracellular reactive oxygen free radicals.

The aim of the present study was to investigate effects of gamma-irradiation on the leukogram of the guppy Poecilia reticulata.

\section{Materials and Methods}

The experiment was carried out on 60 female guppies Poecilia reticulata from our laboratory breeding colony. The body weight of the guppies varied from $5 \mathrm{~g}$ to $6 \mathrm{~g}$ (females). The experiment was approved by the Ethics Committee. The guppies were maintained under constant ambient conditions, i.e. water with a temperature of $24{ }^{\circ} \mathrm{C}$, water filtration, artificial aeration, $\mathrm{Ca}+\mathrm{Mg}$ at the concentration of $0.7 \mathrm{mmol} / \mathrm{l}, \mathrm{pH} 7.04$, light regimen 12:12 h (OECD 1992).

The fish were fed live organisms (Artemia franciscana) and flaky and granular fodder (AQUA EXOTIC, Kapušany, Slovakia). The fish used for the experiment were selected at random, divided into 6 groups, 10 guppies in each, kept under standardized conditions and fed Artemia franciscana, granular fodder (Super Mix $1000 \mathrm{ml}$ ), frozen spinach and frozen grated fillet. Five groups were experimental and one served as a control. Fifteen litre aquaria were used to keep control and experimental fish during the experiment. The experimental fish were exposed to gamma-radiation at a single dose of $20 \mathrm{~Gy}$ using a Chisostat ( ${ }^{60} \mathrm{Co}$ source; dose rate of $1.048 \mathrm{~Gy} / \mathrm{min}$ ). They were irradiated in Petri dishes in aquarium water, using a water column of $1 \mathrm{~cm}$. The control fish were shamexposed, i.e. they were subjected to same procedure as experimental fish except for gamma-irradiation.

Blood of the experimental fish was sampled on days 3, 7, 10, 15, and 20 post-irradiation by intracardial puncture and aspiration into a heparinised ground capillary of volume $60 \mu 1$. Blood samples from the control group were taken and examined at the beginning of the experiment. We prepared a blood smear to determine the differential count, after panoptic staining, the number of individual types of leukocytes, i.e. basophil granulocytes (Ba), eosinophil granulocytes (Eo), neutrophil granulocytes (Ne), lymphocytes (Ly), and monocytes (Mo).

For 20 days post-irradiation we observed and recorded daily food intake and all the changes observed on the surface of experimental guppy bodies.

After collection of blood we carried out pathological-anatomical and histological examination using standard methods. All samples of fish were fixed in 3\% neutral formol and embedded in paraffin. Histological sections of $7 \mu \mathrm{m}$ thickness were stained with haematoxylin-eosin. They were viewed under a JENAMED optical microscope equipped with a micro-camera.

The results obtained were evaluated statistically using one-way ANOVA (GraphPad Prism 3.0 for Windows, GraphPad Software, San Diego, California, USA), the mean values and their differences were evaluated by means of a Tukey multiple comparison test. Differences were considered significant at $P<0.05$.

\section{Results}

In the first days after irradiation the fish were timid and lethargic. The food intake was decreased, which led to marked emaciation. After irradiation the fish dwelled at the bottom of the aquarium.

The first macroscopically visible changes on the bodies of irradiated fish included bilateral exophthalmia. For all experimental groups exposed to radiation, fading of the colour of the body occurred. Haemorrhages began to appear approximately 8 to 12 days after irradiation. The most severe haemorrhages were present in the region of gills.

Our haematological examination of the irradiated fish showed marked quantitative changes in white blood cell picture (Plate III, Fig. 1).

The mean number of the individual types of leukocytes in the blood of the control and experimental fish sampled on days $3,7,10,15$, and 20 after irradiation with gamma rays is shown in Table 1.

Examination of irradiated fish showed haemorrhages on the serosae body cavity and signs of fatty liver (Plate III, Fig. 2). The liver was coloured yellow, slightly enlarged, of fragile consistency. We also observed considerably enlarged gallbladder. For all gutted fish the guts were empty.

\section{Discussion}

Haematopoiesis of fish is affected by both exogenic (water temperature, concentration of $\mathrm{O}_{2}$, natural seasonal cycles, nutrition, and others) and endogenic factors (fish species, 


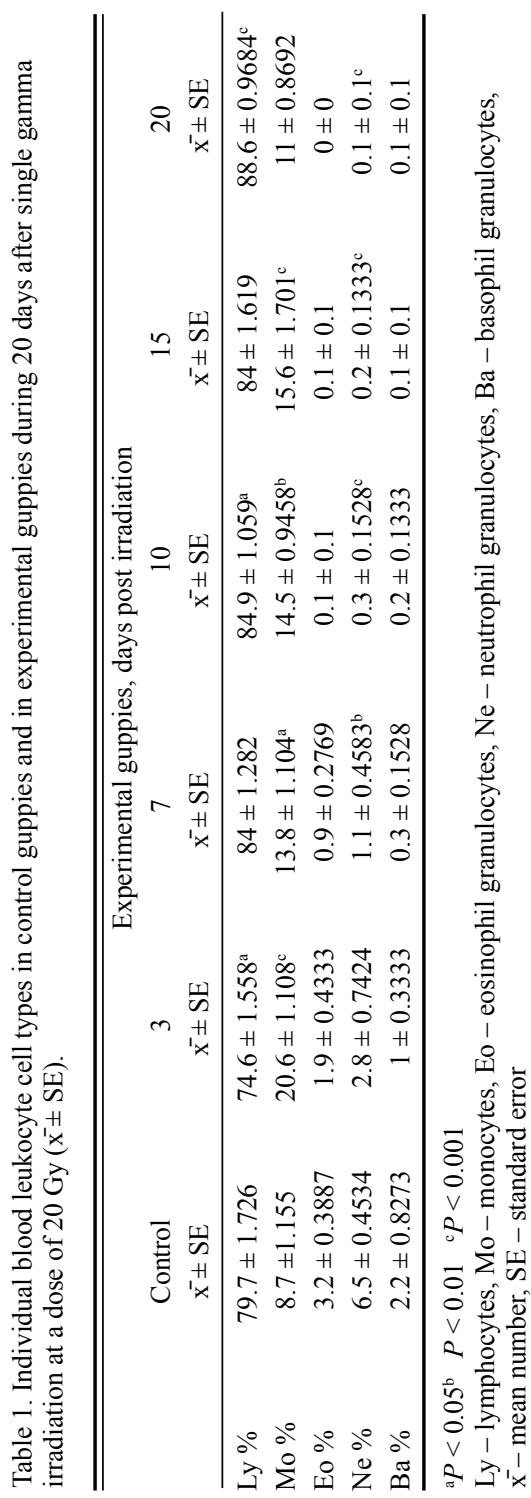

breeding line, age, sex, reproductive cycle, body condition, health, and others) (Doubek 2003).

We observed timidity, lethargy, bilateral exophthalmia, emaciation, intravital haemorrhages and fading out. These symptoms were identical to changes described by Beňová et al. (2006; 2009).

Sesztáková et al. (1996) irradiated 37-dayold broiler chickens with gamma rays and recorded a significant eosinopaenia at 1 to $6 \mathrm{~h}$ post-irradiation and a marked decrease in basophilic granulocytes $24 \mathrm{~h}$ post-irradiation. In our experiments on guppies, we observed a marked decrease in all types of granulocytes by day 3 post-irradiation in comparison with the control. By day 7 post-irradiation, we observed a significant decrease in the relative count of neutrophilic granulocytes.

Sesztáková et al. (2003) recorded eosinophaenia, lymphocytopaenia, and monocytopaenia in irradiated rats, and basophaenia, eosinophaenia, heterophilia, and lymphocytopaenia in irradiated 28-day-old chickens, and also monocytosis after 6 and $24 \mathrm{~h}$ after irradiation at a dose of $4.5 \mathrm{~Gy}$.

According to Pádua et al. (2009), the physiological values for the species Salminus brasiliensis are as follows; lymphocytes $87 \%$, monocytes $2.4 \%$, eosinophils $2.1 \%$, neutrophils $5.6 \%$ and basophils $1.2 \%$.

In our experiments, single irradiation with the dose of 20 Gy resulted in a significant decrease in the relative count of lymphocytes and a significant increase in relative count of monocytes by day 3 after irradiation. The results of Procházka and Dvořák (2002) revealed that fish are much more radioresistant compared to domestic animals (mammals, birds).

An interesting observation was the increased proportion of relative monocyte count which indicated a decline in the relative number of lymphocytes, probably due to stress and glucocorticoids produced by the alarm response of the body shortly after irradiation. According to Sancheti and Goyal (2007), lymphocytes in mice peripheral blood show the highest radiosensitivity. Observations of these authors indicated practically a complete loss of organism defences. Also mice irradiated with gamma rays showed a significant decrease in leukocyte counts within the first $24 \mathrm{~h}$ post-irradiation. This decrease was induced by direct irradiation with a dose of $3 \mathrm{~Gy}$. Also later a decrease in lymphocytes was observed which was caused by lower migration of lymphocytes into the peripheral blood (Waghmare et al. 2011). Livers from irradiated rats were characterized by steatosis of hepatocytes (Christiansen et al. 2006). 
Our study provided important information on the effect of gamma-irradiation on guppies Poecilia reticulata, particularly with respect to the leukogram, which has not been determined before in this fish. The observed changes corresponded to the findings in other species mentioned above. Dilated gallbladder may be related to the reduced food intake and decelerated emptying of the bile.

\section{Acknowledgements}

The study was supported by the grant VEGA No. 1/0423/08. The authors wish to thank for the financial support from the project.

\section{References}

Beňová K, Cigánková V, Falis M, Šmajda B 2006: Clinical symptoms and histological changes in Poecilia reticulata following gamma-rays irradiation. Acta Vet Brno 75: 557-560

Beňová K, Dvořák P, Halán M, Kaleničová Z, Sehnálková H, Cigánková V 2009: Effects of gamma-irradiation on microbial contamination and on histological changes of muscle in Poecilia reticulata. Acta Vet Brno 78: 173-177

Beňová K, Strišková K, Dvořák P 2007: Postirradiational changes in hematological parameters and in intestinal microflora in rats. Acta Facultatis Ecologiae 16: 33-36

Bukhari AS, Mohamed HES, Broos KV, Stalin A, Singhal RK, Venubab P 2012: Histological variations in liver of freshwater fish Oreochromis mossambicus exposed to ${ }^{60}$ Co gamma irradiaton. J Environ Radioact 113: 57-62

Doubek J 2003: Veterinary Haematology (in Czech). $1^{\text {st }}$ ed., Novico a. s., Brno, 464 p.

Christiansen H, Batusic D, Saile B, Hermann RM, Dudas J, Rave-Frank M, Hess CF, Schmidberger H, Ramadori $\mathrm{G}$ 2006: Identification of genes responsive to gamma radiation in rat hepatocytes and rat liver by cDNA array gene expression analysis. Radiat Res 3: $318-25$

Chua MLK, Somaiah N, A'Hern R, Davies S, Gothard L, Yarnold J, Rothkamm K 2011: Residual DNA and chromosomal damage in ex vivo irradiated blood lymphocytes correlated with late normal tissue response to breast radiotherapy. Radiother Oncol 99: 362-366

Lešník F, Danko J 2005: Medical lymphology (in Slovak). Hajko and Hajkova Publishing, Bratislava, 415 p.

OECD 1992: Guideline for Testing of Chemicals. Adopted by the Council on $17^{\text {th }}$ July 1992 . Fish, Acute toxicity test, $9 \mathrm{p}$.

Pádua SB, Ishikawa MM, Satake F, Hisano H, Taveres-Dias M 2009: Blood cells, leucogram and thrombogram of juveniles dourado (Salminus brasiliensis) in experimental conditions of culture. Rev Bras Med Vet 31: 282-287

Procházka Z, Dvořák P 2002: Veterinary Radiobiology and Radiation Hygiene (in Czech). Veterinary and Pharmaceutical University, Brno, 125 p.

Sancheti G, Goyal PK 2007: Prevention of radiation induced hematological alterations by medicinal plant Rosmarinus officinalis in mice. Afr J Trad CAM 4: 165-172

Sesztáková E, Beňová K, Falis M, Škardová I, Toropila M 2003: Radiosensitivity of blood elements in birds and mammals (in Czech). 10 $0^{\text {th }}$ conference of Animal Protection and Welfare, VFU Brno, September 24, pp. $153-155$

Sesztáková E, Toropila M, Beňová K 1996: Post-irradiation changes in the peripheral blood of chickens. Folia Vet 40: 87-90

Vasumathy R, Pandey BN, Mishra KP 2012: Oxidative stress-mediated apoptotic death in human peripheral blood lymphocytes treated with plasma from gamma irradiated blood. J Environ Pathol Toxicol Oncol 31: 1-6

Waghmare G, Waghmare S, Chavan R, Mane D 2011: Leucocytes response in mice to low level gamma irradiation and their protection by Liv. 52. J Biosci Technol 2: 405-409 
Plate III

Renčko A. et al.: Effect of gamma- ... pp. 209-212

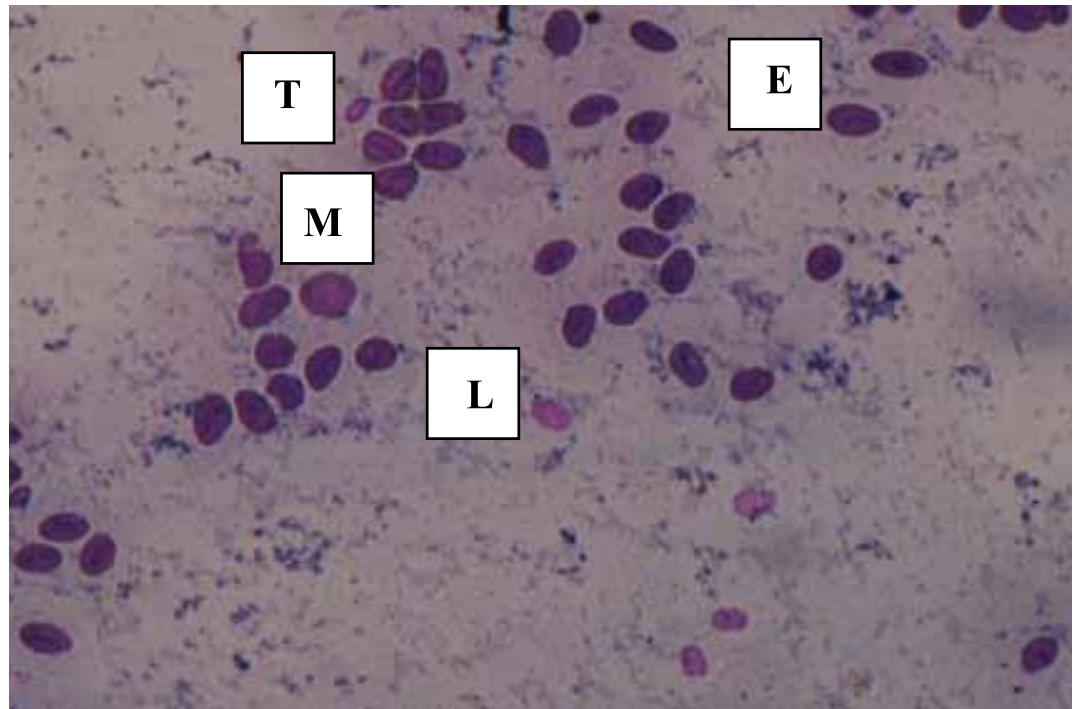

Fig. 1. Blood smear from female Poecilia reticulata on day 3 after exposure to gamma radiation at a dose of 20 Gy.

L - lymphocyte, M - monocyte, E - erythrocyte, T - thrombocyte

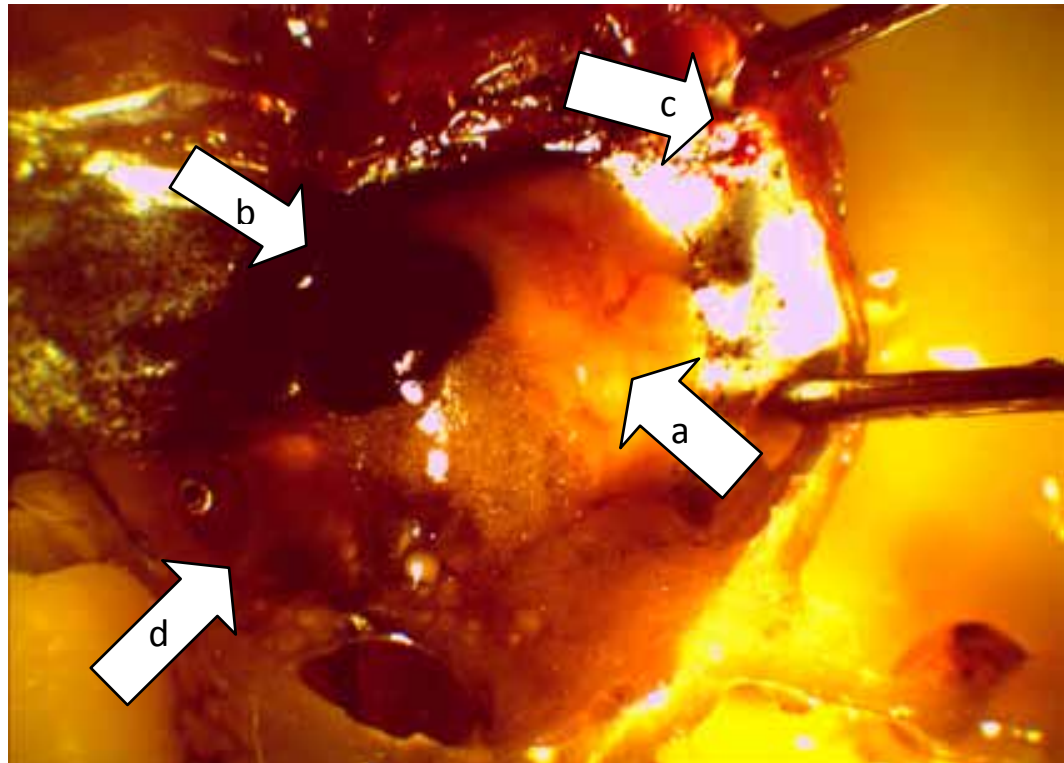

Fig. 2. Female Poecilia reticulata 20 days after exposure to gamma radiation at a dose of 20 Gy. $\mathrm{a}$ - fatty-liver, $\mathrm{b}$ - spleen, $\mathrm{c}$ - haemorrhages on the serosa of a body cavity, $\mathrm{d}$ - embryo 